OPEN ACCESS

Edited by:

Riham Salah El Dine,

Cairo University, Egypt

Reviewed by:

Josipa Vlainic,

Rudjer Boskovic Institute, Croatia

Xiangping Chu,

University of Missouri-Kansas City,

United States

*Correspondence: Agata Małek

a.malek9506@gmail.com Jacek Kurzepa

kurzepa@yahoo.com

Specialty section:

This article was submitted to

Neuropharmacology,

a section of the journal

Frontiers in Neuroscience

Received: 11 October 2021

Accepted: 24 January 2022

Published: 11 February 2022

Citation:

Małek A, Kocot J, Mitrowska K, Posyniak A and Kurzepa J (2022) Bee Venom Effect on Glioblastoma Cells

Viability and Gelatinase Secretion.

Front. Neurosci. 16:792970

doi: 10.3389/fnins.2022.792970

\section{Bee Venom Effect on Glioblastoma Cells Viability and Gelatinase Secretion}

\author{
Agata Małek $^{1 *}$, Joanna Kocot ${ }^{1}, K_{\text {Kamila Mitrowska }}^{2}$, Andrzej Posyniak ${ }^{2}$ and \\ Jacek Kurzepa ${ }^{1 *}$ \\ ${ }^{1}$ Department of Medical Chemistry, Medical University of Lublin, Lublin, Poland, ${ }^{2}$ Department of Pharmacology \\ and Toxicology, National Veterinary Research Institute, Puławy, Poland
}

Background: The involvement of MMP-2 and MMP-9 in the pathogenesis of various kinds of cancers including glioblastoma is well documented. The evaluation of the anticancer potential of honey bee (Apis mellifera) venom (BV) consisting of the inhibition of MMP-2 and MMP-9 secretion in a glioblastoma cell culture model was the aim of the study.

Methods: 8-MG-BA and GAMG human primary glioblastoma cell lines vs. HT-22 mouse hippocampal neuronal cells were applied for the study. The BV dose $(0.5,1.0,1.25$, $1.5,1.75,2.0,2.5$, and $5.0 \mu \mathrm{g} / \mathrm{ml})$ and time-dependent $(24,48,72 \mathrm{~h})$ cytotoxicity was evaluated with the tetrazolium-based colorimetric assay (MTT test). MMP-2 and MMP-9 activities in the cell culture medium under different BV concentrations were determined by gelatin zymography.

Results: A dose and time-dependent BV effect on cytotoxicity of both glioblastoma cell lines and hippocampus line was observed. The weakest, but statistically important effect was exerted by BV on HT-22 cells. The greatest cytotoxic effect of BV was observed on the 8-MG-BA line, where a statistically significant reduction in viability was observed at the lowest BV dose and the shortest incubation time. The reduction of both gelatinases secretion was observed at 8-MG-BA and GAMG lines without significant effect of HT22 cell line.

Conclusion: In vitro studies indicate that BV has both cytotoxic and inhibitory effects on the secretion of MMP-2 and MMP-9 in selected lines of glioma, suggesting anticancer properties of BV.

Keywords: bee venom, glioblastoma, anticancer potential, MMP-2, MMP-9

\section{INTRODUCTION}

Clinically, the classification of gliomas includes four grades, with grade four glioblastoma representing the most malignant type and also known as glioblastoma multiforme (GBM) (Atiq and Parhar, 2020). GBM is a highly aggressive brain tumor. Different grade GBMs are the most frequent primary malignant brain tumors (15\% of all intracranial neoplasms and up to $50 \%$ of all primary malignant brain tumors) (Linhares et al., 2020). Despite significant progress in GBM treatment 
research, it remains a great therapeutic challenge. Current treatment methods include surgical tumor resection with chemotherapy and radiotherapy thereafter. However, even with advanced surgical techniques such as e.g., fluorescence-guided resection, the complete removal of cancer cells is almost impossible because tumor cells located at the edges of tumors in perivascular niches remain in most cases (Atiq and Parhar, 2020). Therefore, the new kind of therapy together with the applying of various natural compounds seems to be an interesting research topic that gives hope for finding an effective treatment for glioblastoma. Bee venom (BV) is a biotoxin (apitoxin) synthesized and secreted by a venom gland placed in the abdominal cavity of a bee. BV is a complex mixture containing several biologically active components with a variety of pharmaceutical properties (Rady et al., 2017; Carpena et al., 2020). The most prevalent component of BV is a representative polypeptide group-melittin, composed of 26 amino acids. Phospholipase $\mathrm{A}_{2}\left(\mathrm{PLA}_{2}\right)$ is believed to be the second most abundant one (Choo et al., 2010; Sciani et al., 2010; Lee et al., 2016), while the third component is apamine (Rady et al., 2017). In BV samples collected from honey bees (Apis mellifera) in Poland, the content of the mentioned substances has been amounted to $61.15-70.15 \%$ (average $64.40 \%$ ) for melittin, 11.24$15.05 \%$ (average $13.00 \%$ ) for $\mathrm{PLA}_{2}$ and $2.09-4.18 \%$ (average $3.10 \%$ ) for apamine (Rybak-Chmielewska and Szczęsna, 2006).

The anticancer properties or the ability to prevent the chemotherapy-induced side effects of BV as well as its selective components have already been reported. Jamasbi et al. (2018) have revealed the effectiveness of melittin against gastric cancer cells. The authors compared the monomeric form of this peptide with its dimer form and found the former being more cytotoxic at low concentrations $(1-5 \mu \mathrm{M})$, while at higher concentrations (10 $\mu \mathrm{M})$ the cytotoxic effect of both forms was comparable. Kim et al. (2015), in turn, proved that PLA 2 could prevent inflammatory responses in cisplatin-induced acute kidney injury. According to Zhou et al. (2013) both melittin and apamine have been shown to trigger apoptotic cell death in hepatocellular carcinoma cells (HepG2). Zheng et al. (2015) in turn, suggested that BV could inhibit colon cancer cell growth, and its antiproliferative effect may be related to the induction of apoptosis by activation of DR4 and DR5 and inhibition of NF- $\mathrm{BB}$ signaling pathway.

When considering the therapeutic properties of $\mathrm{BV}$ components against the tumor located within the Central Nervous System (CNS), their ability to penetrate the blood-brain barrier (BBB) should be especially considered. Earlier studies show that both apamine and melittin have the ability to cross the $\mathrm{BBB}$, which allows the $\mathrm{BV}$ components to be considered as chemical compounds with potential therapeutic properties exhibiting activity within the CNS (Upadhyay, 2014; Wehbe et al., 2019).

Matrix metalloproteinases (MMPs), including gelatinases (MMP-2 and MMP-9), exert pleiotropic effects under pathological and physiological conditions (BoguszewskaCzubara et al., 2019; Drankowska et al., 2019). MMPs also play a key role in cancer invasion and metastasis. Many studies have reported elevated MMPs expression and/or activity in cancer cells that metastasize to distant organs including the lungs, liver, lymph nodes, or adrenal medullary (Yelken et al., 2017). MMP-9 has been considerably involved in glioblastoma progression. Its overexpression correlates with increased invasive glioma grades, whereas a decrease of MMP-9 expression is associated with favorable outcome and response to Temozolomide treatment (Quesnel et al., 2020). Zhang et al. (2019) reported the positive expression of MMP-2 in glioma was closely related to the tumor diameter, severity of peritumoral edema, degree of enhancement, and pathological grade of tumor observed in magnetic resonance imaging (MRI). In addition, MMP-2 was highly expressed in brain glioma, and it was considered as a negative factor for prognosis (Zhang et al., 2019).

In the available literature data, studies evaluating the ability of BV to inhibit glioblastoma cell growth and metastasis are scarce. Considering this fact, the aim of the current study was to examine the in vitro influence of BV on cell viability and the BV induced secretion of MMP-2 and MMP-9 by glioblastoma cell lines (GAMG, 8-MG-BA) vs. hippocampal cells (HT-22).

\section{MATERIALS AND METHODS}

\section{Bee Venom}

Samples of Apis mellifera bee venom were collected from a private apiary located in Siedliszcze (Lublin region, Eastern Poland), by stimulating the bees with electric current pulses using Bee Venom Collector BVC 5.02017 (IGK Electronics Ltd., Varna, Bulgaria). The general scheme of bee venom collection procedure was illustrated by in Ref. (Carpena et al., 2020). The samples collected between May and September 2017 were pooled together and stored in the dark at $5^{\circ} \mathrm{C}$ until analysis (Rybak-Chmielewska and Szczęsna, 2006; Kokot et al., 2009). The bee venom stock solution of $1 \mathrm{mg} / \mathrm{ml}$ in PBS was prepared, vortexed for $1 \mathrm{~min}$, sonicated for $10 \mathrm{~min}$, and filtered (Matysiak et al., 2011). The stock solutions were prepared directly before each experiment and then diluted in a complete medium to obtain the required concentration.

\section{The Determination of Melittin Content in the Bee Venom Sample}

The determination of melittin content was performed in Department of Pharmacology and Toxicology of the National Veterinary Research Institute (Poland) by liquid chromatography with tandem mass spectrometry (LC-MS/MS) according to the method of Zhou et al. (2010) with some modifications. Briefly, the bee venom sample (2 mg) was weighed and dissolved in $1 \mathrm{ml}$ of water followed by vortexing for $5 \mathrm{~min}$. Next, the tube was centrifuged at $10,000 \mathrm{rpm}$ at $4^{\circ} \mathrm{C}$ for $10 \mathrm{~min}$. The supernatant was filtered through a $0.22-\mu \mathrm{m}$ nylon syringe filter and diluted 100 times with $0.1 \%$ formic acid before the LCMS/MS analysis. For separation and identification of melittin in BV extract, an ExionLC AC system consisting of a binary gradient pump, autosampler, column oven, and system controller coupled to QTRAP 5,500 linear ion trap quadrupole mass spectrometer (AB Sciex) with electrospray ionization (ESI) interface was used. Data acquisition and analysis were accomplished with Analyst 1.6.3. Mass spectrometric analysis was performed in positive ESI mode. The following instrument conditions were used: ion 


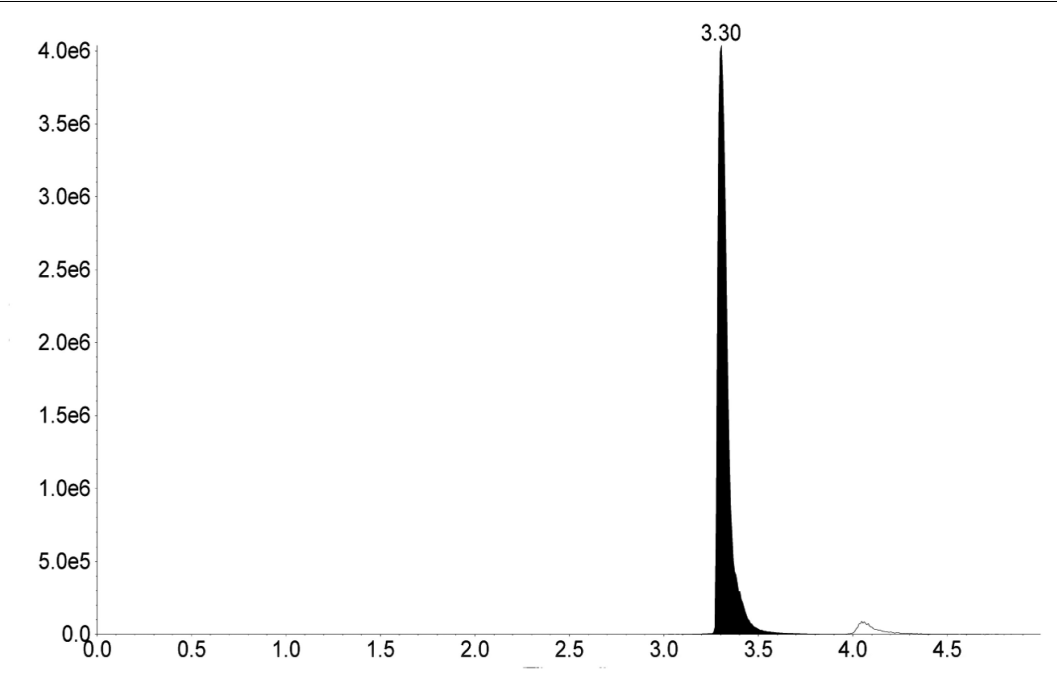

FIGURE 1 | MRM chromatogram of melittin (m/z 712.8-> 70.0) in the bee venom sample.

source temperature $300^{\circ} \mathrm{C}$, curtain gas 20 psi, nebulizer gas 50 psi, heater gas $60 \mathrm{psi}$, ion spray voltage 3,500 V. Quantitation of analyte was performed by monitoring the following SRM transitions: $\mathrm{m} / \mathrm{z} 712.8->70.0$, collision energy $140 \mathrm{~V}$ with dwell time $100 \mathrm{~ms}$. The chromatographic separation was performed on a Kinetex octadecyl analytical column $(2.6 \mu \mathrm{m}, 150 \times 2.1 \mathrm{~mm})$ with an octadecyl guard cartridge (Phenomenex, Torrance, CA, United States). The mobile phase A consisted of $0.1 \%$ formic acid in acetonitrile, while the mobile phase B contains $0.1 \%$ formic acid in water. Linear gradient steps were used with initial conditions set at $5 \%$ of the mobile phase A, held for $0.5 \mathrm{~min}$, increasing to $95 \%$ from 0.51 to $2.00 \mathrm{~min}$, and then returned to the initial composition of the mobile phase A (5\%) from 2.01 to $5.00 \mathrm{~min}$. The flow rate of the mobile phase was $0.25 \mathrm{ml} / \mathrm{min}$. The column temperature was $30^{\circ} \mathrm{C}$ and the injection volume was $5 \mu \mathrm{l}$.

\section{Cell Culture}

The human glioblastoma cell lines were obtained from Leibniz Institute, DSMZ-German Collection of Microorganisms and Cells Cultures GmbH (GAMG-ACC 242; 8-MG-BA-ACC 432). As control cells, immortalized mouse hippocampal cell line, HT-22 (Sigma Aldrich, Saint Louis, MO, United States) was used. The cells were cultured in Dulbecco's Modified Eagle Medium (DMEM), GAMG and HT-22 and in Eagle's Minimum Essential Medium (EMEM) - 8-MG-BA, supplemented with 10\% $(\mathrm{v} / \mathrm{v})$ fetal bovine serum, penicillin $(10,000 \mathrm{U} / \mathrm{ml})$, streptomycin $(10 \mathrm{mg} / \mathrm{ml})$ and amphotericin B $(250 \mu \mathrm{g} / \mathrm{ml})$. The cells were incubated at $37^{\circ} \mathrm{C}, 5 \% \mathrm{CO}_{2}$ atmosphere. The cells were maintained in the logarithmic growth phase by regular passage at $80 \%$ confluence.

\section{Cell Viability Assay}

The cytotoxicity of the bee venom was studied against human glioblastoma cell lines (GAMG and 8-MG-BA) vs. neuronal (hippocampal) cell line (HT-22) used as a control line. After 24$\mathrm{h}$ incubation in growth medium with an addition of $10 \%$ fetal bovine serum (FBS) on 96-well plates, the cells were treated with the following concentrations of bee venom: 0 (vehicle), $0.5,1.0,1.25,1.5,1.75,2.0,2.5$, and $5.0 \mu \mathrm{g} / \mathrm{ml}$ in medium without FBS. The cells were cultured at $37^{\circ} \mathrm{C}$ in the presence of $5 \% \mathrm{CO}_{2}$-air for the next 24,48 , and $72 \mathrm{~h}$. The bee venom cytotoxicity was evaluated using the MTT colorimetric method based on the ability of viable cells to the transformation of yellow, soluble tetrazolium salts [3-(4,5-dimethylthiazol-2-yl)2,5-diphenyltetrazolium bromide, MTT] to purple insoluble formazan, by cellular dehydrogenases. After incubation with bee venom solution, cell cultures were supplemented with $10 \mu \mathrm{l}$ per well of $5 \mathrm{mg} / \mathrm{ml}$ MTT (Sigma-Aldrich, Saint Louis, MO, United States) stock in PBS, and the incubation was continued for $4 \mathrm{~h}$ at $37^{\circ} \mathrm{C}$. Next, the medium with MTT was removed, and the formed crystals were dissolved in $100 \mu \mathrm{l}$ of DMSO. The solution absorbance was measured at $570 \mathrm{~nm}$, using a spectrophotometric plate reader Epoch, BioTek Instruments (Vermont, United States). The relative cytotoxic activity was determined as the amount of bee venom capable of reducing 50\% of cell viability (IC50 value). The experiment was performed three times with triplicates for each concentration.

\section{Analysis of Matrix Metalloproteinase-2 and Matrix Metalloproteinase-9 Activity in Cell Culture Supernatants}

After 72-h incubation with the following concentration of BV $1.0,1.5,2.0,2.5,5.0 \mu \mathrm{l} / \mathrm{ml}$, the media from the cells were collected to measure the secreted MMP-2 and MMP-9 activities. The concentrations of BV used for MMPs analysis as well as the $72 \mathrm{~h}$ incubation time were chosen on the base of the cell viability assay. The experiment was performed three times with duplicates for each concentration $(n=6)$. MMP-2 and MMP9 activities were evaluated with the use of gelatin zymography according to previously applied methods (Golab et al., 2014). Briefly, $80 \mu \mathrm{l}$ of cell culture media was mixed with $20 \mu \mathrm{L}$ of 
sample loading buffer containing $10 \%$ sodium dodecyl sulfate (SDS) and incubated for $30 \mathrm{~min}$ at room temp. Next, the proteins were separated by polyacrylamide gel electrophoresis (PAGE) on a $10 \%$ gel supplemented with $0.05 \%$ gelatin type A from porcine skin; G2500 (Sigma-Aldrich, St. Louis, MO, United States). After electrophoresis, the gels were washed with $2.5 \%$ Triton X-100 three times for 20 min each to remove SDS. Next, 48 -h-incubation was performed at $37^{\circ} \mathrm{C}$ in the buffer $\mathrm{pH}$ 7.2 containing $1 \%$ Triton X-100. The gels were stained with the solution containing 0.1\% Coomassie Blue R-250, 20\% methanol, and $10 \%$ glacial acetic acid in distilled water and destained in $10 \%$ solution of acetic acid thereafter. The MMP-2 and MMP9 were detected as colorless bands (digested gelatin) on a blue background (undigested gelatin). Zymography allows detecting both pro-active (latent) and active forms of MMPs as the SDS is used to activate non-proteolytic pro-MMPs into MMPs with catalytical activity without changing their molecular mass. The enzymes were identified by comparing their localization with molecular mass standards (SM0441) (Fermentas Life Sciences, St. Leon-Rot, Germany). Zymographic gels were scanned and quantified with ImageJ software (National Institute of Health, Bethesda, MD, United States). The activities of MMP-2 and MMP-9 were expressed as the optical density (OD) of the substrate lysis zone.

\section{Statistical Analysis}

Statistical analysis was performed using GraphPad Prism 8 software. Non-linear regression (curve fit) was used to establish IC50 values of BV after 24, 48, and $72 \mathrm{~h}$ of incubation for all three cell lines. The results of cells viability were expressed as mean values as well as standard deviation, and the statistical significance of the differences between the control vehicle and the other groups of each three cell lines in 3 time points was evaluated using a two-way analysis of variance (ANOVA) followed by Tukey's post-hoc test. Values were considered significant with $p<0.05$.

\section{RESULTS}

\section{Melittin Content in Bee Venom}

Melittin content in the bee venom sample was found to be $69.0 \pm 0.1 \%$ of dry weight (Figure 1).

\section{The Effect of Bee Venom on Cells Viability in vitro (IC50 Estimation)}

To analyze the effect of BV on cells viability, the inhibitory concentration of BV (IC50) was assessed depending on the incubation time; 24,48 , and $72 \mathrm{~h}$. The most significant timedependent effect of BV was observed on GAMG cells, where the increase of incubation time from 24 to $72 \mathrm{~h}$ decreased the IC50 from 1.519 to $0.274 \mathrm{ng} / \mathrm{ml}$ (more than 5 -fold reduction in BV dose when incubated for 72 vs. $24 \mathrm{~h}$ ). The lowest value of BV IC50 after $24 \mathrm{~h}$ incubation was noticed for 8-MG-BA cells $(0.7027 \mathrm{ng} / \mathrm{ml})$. IC50 for these cells did not change significantly after longer incubation times $(0.6998$ and $0.6527 \mathrm{ng} / \mathrm{ml}$ after 48 and $72 \mathrm{~h}$, respectively). The highest IC50 value of BV was noticed for HT-22 cells at each of the time intervals, suggesting the low sensitivity of these cells to BV. The increase of incubation time from 24 to $72 \mathrm{~h}$ resulted in the decrease of IC50 value for HT-22 from $2.259 \mathrm{ng} / \mathrm{ml}$ to $1.383 \mathrm{ng} / \mathrm{ml}$ for HT-22 cells. All results were expressed in Figure 2.

\section{The Bee Venom Effect on Matrix Metalloproteinase-2 and Matrix Metalloproteinase-9 Secretion}

The dose-dependent effect of BV on MMP-2 and MMP-9 secretion from GAMG and 8-MG-BA cells was revealed. After $72 \mathrm{~h}$ of incubation with BV at concentration $1.5 \mu \mathrm{l} / \mathrm{ml}$ and higher, the significant reduction of MMP-2 and MMP-9 secretion from GAMG cells was noticed. Similar inhibitory effect was observed on 8-MG-BA cells, however, a statistical significant reduction of gelatinase secretion was already observed at BV concentration of $1.0 \mu \mathrm{l} / \mathrm{ml}$. There was no significantly visible effect of BV on MMP-2 and MMP-9 secretion from HT-22 cells at any analyzed concentrations. The representative zymograms were shown in Figure 3.

\section{DISCUSSION}

Among the various agents that influence the development, progression, and metastasis of cancer, there are many natural compounds that have pleiotropic properties and possess chemopreventive potential, e.g., soybean isoflavones, curcumin, retinoids, resveratrol, epigallocatechin or cannabinoids. Some effects of them are well documented in the literature, for example, curcumin, resveratrol are known as strong antioxidants. The anticancer potential of the remaining compounds requires further research, as is the case with, for example, cannabinoids; animal studies showed that the activation of cannabinoid receptors 1 and 2 by tetrahydrocannabinol (THC) results in impaired proliferation and invasion of cancer cells, induces apoptosis (accumulation of ceramides in culture), and further reduces the tumor volume (McAllister et al., 2005; Galanti et al., 2008; Marcu et al., 2010; Abrams, 2016). Therapeutic administration of bee venom to treat various diseases, initially primarily arthritis or ailments related to joints and muscles, has been used in traditional Chinese medicine from 1,000 to 3,000 BC (Zhang et al., 2018). The application of BV is widespread in the treatment of not only immune-mediated diseases but also cancer. Both in vitro and in vivo studies have confirmed that the main BV constituent, melittin, is responsible not only for the cytotoxic effect, but also for the immunomodulatory and proapoptotic effect against various types of cancer cells (Oršolić, 2012). BV has been shown to have an antiproliferative effect on cancer cells via several mechanisms. It induces apoptosis through the activation of death DR4 and DR5 death receptors. In addition, melittin reduces tumor growth and metastasis (Liu et al., 2002). BV inhibits cancer cells growing also due to the activation of caspase 3 and 9 pathways and inhibition of NF- $\kappa \mathrm{B}$ pathway signaling, leading to inhibition of the expression of proliferative and antiapoptotic genes encoding Bcl-2, cyclooxygenase-2 (COX-2), 

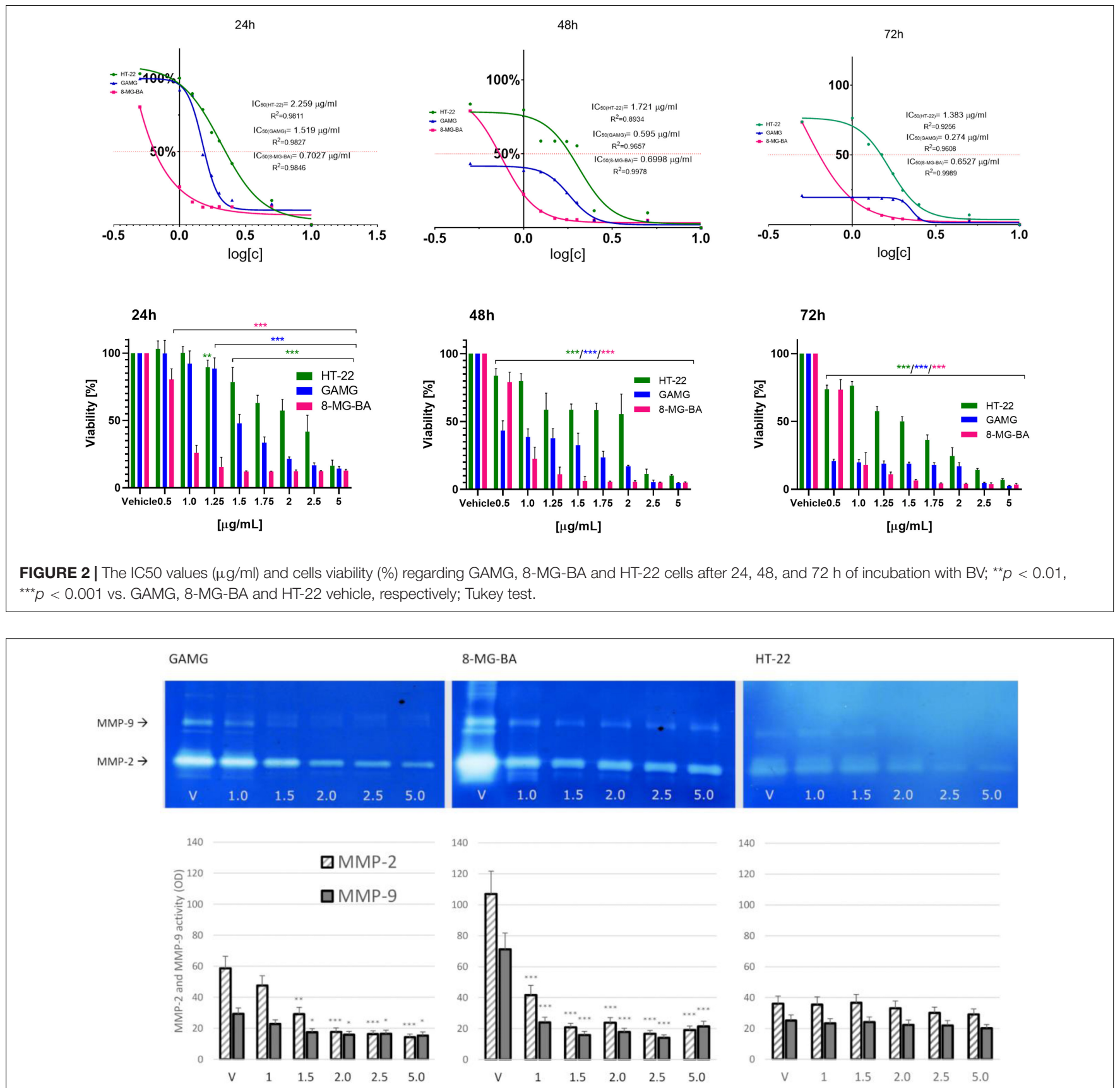

FIGURE 3 | BV effect on MMP-2 and MMP-9 secretion from GAMG, 8-MG-BA, and HT-22 cells. Significant decrease of gelatinase secretion was observed in GAMG and 8-MG-BA cells after $72 \mathrm{~h}$ of incubation with different concentrations of BV. The effect of BV on MMP-2 and MMP-9 secretion from HT-22 cells did not reach statistical significance. ANOVA with Tukey post-hoc test. ${ }^{\star} p<0.05,{ }^{\star \star} p<0.01,{ }^{\star \star \star} p<0.01$ compared to controls $(\mathrm{V}$, vehiculum).

cellular inhibitor of apoptosis 2 (cIAP-2), inducible nitric oxide synthase (iNOS) and cytosolic phospholipase A2 (cPLA2) (Park et al., 2014).

Finally, it is worth emphasizing that the potential of BV in the treatment of SARS-CoV-2 infections has also recently been recognized. It has been noted that in Wuhan, China, beekeepers, as a group exposed to frequent bee bites, are more resistant to COVID-19 infection, probably due to regulation of the immune response, which can cause an increase in the titer of $\operatorname{IgE}$ and $\operatorname{IgG}$ antibodies (Kasozi et al., 2020).

The obtained results showed a statistically significant effect of unfractionated bee venom on the viability of glioblastoma cells and physiological hippocampal cells. The observed effect was different for each cell type tested. Earlier reports indicated different chemosensitivity of glioblastoma cell lines (Wolff et al., 1999). Glioblastoma cell malignancy and drug sensitivity are 
related to the cell of origin; nervous stem cell-like origin causes higher malignancy and drug sensitivity than others (Jiang et al., 2017). After an incubation time of $24 \mathrm{~h}, 8-\mathrm{MG}-\mathrm{BA}$ was proved to be more sensitive cells to $\mathrm{BV}$ effects than other tested cell lines; during each applied concentration of $\mathrm{BV}$, the viability of 8-MG-BA cells was the lowest among the analyzed configurations. Moreover, the IC50 for BV was the lowest after $24 \mathrm{~h}$ incubation with respect to 8-MG-BA cells. However, after $48 \mathrm{~h}$ of incubation, the viability of GAMG cells significantly decreased. The IC50 for GAMG decreased threefold compared to the $24 \mathrm{~h}$ incubation and was less than the IC50 for 8-MGBA after $48 \mathrm{~h}$ incubation. Extending the incubation time to $72 \mathrm{~h}$ did not significantly affect the IC50 value for 8-MG-BA cells, however, a decrease in IC50 for GAMG cells was observed at this time of incubation. When GAMG cells were incubated with bee venom for longer periods of time, we observe a significant decrease in cell viability even at lower concentrations compared to shorter incubation times. Thus, the longer the incubation the significantly greater the cytotoxic effect against GAMG cells without the need for higher doses of BV. For GAMG cell line, the incubation time of bee venom also proved to be a significant factor affecting cell viability, and by modifying the treatment time we can obtain a satisfactory effect even at lower doses of active substance. Summarizing this part, the studies showed the dose-dependent and time-dependent sensitivity of the tested cells to bee venom.

The glial cells were more sensitive to BV effects than the nerve cells of the hippocampus. For higher concentrations and/or longer incubation times with bee venom of HT-22 line cells, a reduction in the viability of hippocampal cells used as a control was also observed. Thus, bee venom may exhibit some inhibitory effects on neuronal cell viability in the brain. It is therefore worth emphasizing the necessity of caution in the selection of appropriate doses that will simultaneously be effective against tumor cells and will not significantly affect the viability of neuronal cells, so as not to impair their essential functions that they perform in numerous processes.

Substrate-zymography, applied in this study, still represents the most simple, sensitive, and quantifiable assay for MMPs analysis, which is able to identify, simultaneously in the same sample, the entire panel of enzymes that are capable of degrading a specific substrate. The identification of gelatinase activity is possible by using gelatin as a substrate (gelatin zymography). Moreover, zymography showing the activity of MMPs, but not directly the amount of protein, provides additional information on the activity of these enzymes in the tested sample (Lowrey et al., 2008; Ricci et al., 2016).

The study also showed a dose-dependent effect of bee venom on the secretion and activities of MMP-2 and MMP-9 in the culture medium. When analyzing the activity of both gelatinases

\section{REFERENCES}

Abrams, D. I. (2016). Integrating cannabis into clinical cancer care. Curr. Oncol. 23, S8-S14. doi: 10.3747/co.23. 3099 in GAMG cells, depending on the dose of the BV used for incubation, a gradual reduction in activity can be observed. A statistically significant reduction in MMP-2 and MMP-9 activity was obtained at concentrations higher than $1 \mathrm{mg} / \mathrm{ml}$. The reduction in the activity of gelatinases may be explained simply by the reduced expression and secretion of these enzymes to the extracellular space under the influence of BV. The observed decrease in the activity of MMP-2 and MMP-9 cannot be explained by the decreased cell viability, as cell death under the influence of BV would lead to the release of intracellular reservoirs of MMP-2 and MMP-9 into the medium. In such cases, it could even result in an increase in the activity of these enzymes.

The active ingredients of BV have the ability to pass through the $\mathrm{BBB}$ and can therefore be used in the treatment of diseases of the CNS ( $\mathrm{Gu}$ et al., 2020). BV has proven to be an effective treatment in animal models of Alzheimer's Disease, Parkinson's Disease, Epilepsy, Multiple Sclerosis, and Amyotrophic Lateral Sclerosis (Silva et al., 2015). The sensitivity of several cancer cells, including renal, lung, liver, prostate, bladder, and mammary cancer cells to BV peptides such as melittin and phospholipase A2 together with the known permeability of these peptides through BBB allows to hope that BV may also be active against cancer located in the CNS (Oršolić, 2012).

\section{CONCLUSION}

In conclusion, the performed studies showed a dose and timedependent effect of unfractionated bee venom on the survival of neoplastic cells of glial origin. Moreover, an inhibitory effect on the secretion of both gelatinases was demonstrated, which may have a potential impact on tumor spread.

Further research should focus on elucidating the molecular mechanism of the observed effect and on identifying the active components of the venom exhibiting these properties.

\section{DATA AVAILABILITY STATEMENT}

The raw data supporting the conclusions of this article will be made available by the authors, without undue reservation.

\section{AUTHOR CONTRIBUTIONS}

$\mathrm{JKu}, \mathrm{AM}$, and JKo participated in research design. AM, KM, and AP conducted to the experiments. AM, JKu, KM, and AP wrote and contributed to the writing of the manuscript. JKu supervised the work. JKu and JKo initiated the research. All authors contributed to the article and approved the submitted version.

Atiq, A., and Parhar, I. (2020). Anti-neoplastic potential of flavonoids and polysaccharide phytochemicals in glioblastoma. Molecules 25:E4895. doi: 10 . 3390/molecules25214895

Boguszewska-Czubara, A., Budzynska, B., Skalicka-Wozniak, K., and Kurzepa, J. (2019). Perspectives and new aspects of metalloproteinases' inhibitors in the 
therapy of CNS disorders: from chemistry to medicine. Curr. Med. Chem. 26, 3208-3224. doi: 10.2174/0929867325666180514111500

Carpena, M., Nuñez-Estevez, B., Soria-Lopez, A., and Simal-Gandara, J. (2020). Bee Venom: an updating review of its bioactive molecules and its health applications. Nutrients 12:3360. doi: 10.3390/nu12113360

Choo, Y. M., Lee, K. S., Yoon, H. J., Kim, B. Y., Sohn, M. R., Roh, J. Y., et al. (2010). Dual function of a bee venom serine protease: prophenoloxidase-activating factor in arthropods and fibrin(ogen)olytic enzyme in mammals. PLoS One 5:e10393. doi: 10.1371/journal.pone.0010393

Drankowska, J., Kos, M., Kościuk, A., Marzęda, P., Boguszewska-Czubara, A., Tylus, M., et al. (2019). MMP targeting in the battle for vision: recent developments and future prospects in the treatment of diabetic retinopathy. Life Sci. 229, 149-156. doi: 10.1016/j.lfs.2019.05.038

Galanti, G., Fisher, T., Kventsel, I., Shoham, J., Gallily, R., Mechoulam, R., et al. (2008). $\Delta 9$-Tetrahydrocannabi-nol inhibits cell cycle progression by downregulation of E2F1 inhuman glioblastoma multiforme cells. Acta Oncol. $47,1062-1070$.

Golab, P., Boguszewska-Czubara, A., Kielbus, M., and Kurzepa, J. (2014). The rtPA increases MMP-9 activity in serum during ischaemic stroke. Neurol. Neurochir. Pol. 48, 309-314. doi: 10.1016/j.pinns.2014.07.012

Gu, H., Han, S. M., and Park, K. K. (2020). Therapeutic effects of apamin as a bee venom component for non-neoplastic disease. Toxins 12:195. doi: 10.3390/ toxins 12030195

Jamasbi, E., Lucky, S. S., Li, W., Hossain, M. A., Gopalakrishnakone, P., and Separovic, F. (2018). Effect of dimerized melittin on gastric cancer cells and antibacterial activity. Amino Acids 50, 1101-1110. doi: 10.1007/s00726-0182587-6

Jiang, Y., Marinescu, V. D., Xie, Y., Jarvius, M., Maturi, N. P., Haglund, C., et al. (2017). Glioblastoma cell malignancy and drug sensitivity are affected by the cell of origin. Cell Rep. 18, 977-990. doi: 10.1016/j.celrep.2017.01.003

Kasozi, K. I., Niedbała, G., Alqarni, M., Zirintunda, G., Ssempijja, F., Musinguzi, S. P., et al. (2020). Bee Venom - a potential complementary medicine candidate for SARS-CoV-2 infections. Front. Public Health 8:594458. doi: 10.3389/fpubh. 2020.594458

Kim, H., Lee, H., Lee, G., Jang, H., Kim, S. S., Yoon, H., et al. (2015). Phospholipase A2 inhibits cisplatin-induced acute kidney injury by modulating regulatory $\mathrm{T}$ cells by the CD206 mannose receptor. Kidney Int. 88, 550-559. doi: 10.1038/ki. 2015.147

Kokot, Z. J., Matysiak, J., Kłos, J., Kẹdzia, B., and Hołderna-Kędzia, E. (2009). Application of principal component analysis for evaluation of chemical and antimicrobial properties of honey bee (apis mellifera) venom. J. Apic. Res. Bee. World 48, 168-175. doi: 10.3896/IBRA.1.48.3.04

Lee, K. S., Kim, B. Y., Yoon, H. J., Choi, Y. S., and Jin, B. R. (2016). Secapin, a bee venom peptide, exhibits anti-fibrinolytic, anti-elastolytic, and anti-microbial activities. Dev. Comp. Immunol. 63, 27-35. doi: 10.1016/j.dci.2016.05.011

Linhares, P., Carvalho, B., Vaz, R., and Costa, B. M. (2020). Glioblastoma: is there any blood biomarker with true clinical relevance? Int. J. Mol. Sci. 21:5809. doi: $10.3390 / \mathrm{ijms} 21165809$

Liu, X., Chen, D., Xie, L., and Zhang, R. (2002). Effect of honey bee venom on proliferation of K1735M2 mouse melanoma cells in-vitro and growth of murine B16 melanomas in-vivo. J. Pharm. Pharmacol. 54, 1083-1089. doi: 10.1211/ 002235702320266235

Lowrey, G. E., Henderson, N., Blakey, J. D., Corne, J. M., and Johnson, S. R. (2008). MMP-9 protein level does not reflect overall MMP activity in the airways of patients with COPD. Respir. Med. 102, 845-851.

Marcu, J. P., Christian, R. T., Lau, D., Zielinski, A. J., Horowitz, M. P., Lee, J., et al. (2010). Cannabidiol enhancesthe inhibitory effects of $\Delta 9$ - tetrahydrocannabinol on human glioblastoma cell proliferation and survival. Mol. Cancer Ther. 9, 180-189.

Matysiak, J., Schmelzer, C. E., Neubert, R. H., and Kokot, Z. J. (2011). Characterization of honeybee venom by MALDI-TOF and nanoESI-QqTOF mass spectrometry. J. Pharm. Biomed. Anal. 54, 273-278. doi: 10.1016/j.jpba. 2010.08.020

McAllister, S. D., Chan, C., Taft, R. J., Luu, T., Abood, M. E., Moore, D. H., et al. (2005). Cannabinoids selec-tively inhibit proliferation and induce death of cultured human glioblastoma multiforme cells. J. Neuro Oncol. 74, 31-40. doi: 10.1007/s11060-004-5950-2

Oršolić, N. (2012). Bee venom in cancer therapy. Cancer Metastasis Rev. 31, 173-194. doi: 10.1007/s10555-011-9339-3
Park, H. G., Kyung, S. S., Lee, K. S., Kim, B. Y., Choi, Y. S., Yoon, H. J., et al. (2014). Dual function of a bee (Apis cerana) inhibitor cysteine knot peptide that acts as an antifungal peptide and insecticidal venom toxin. Dev. Comp. Immunol. 47 , 247-253. doi: 10.1016/j.dci.2014.08.001

Quesnel, A., Karagiannis, G. S., and Filippou, P. S. (2020). Extracellular proteolysis in glioblastoma progression and therapeutics. Biochim. Biophys. Acta Rev. Cancer 1874:188428. doi: 10.1016/j.bbcan.2020.188428

Rady, I., Siddiqui, I. A., Rady, M., and Mukhtara, H. (2017). Melittin, a major peptide component of bee venom, and its conjugates in cancer therapy. Cancer Lett. 402, 16-31. doi: 10.1016/j.canlet.2017.05.010

Ricci, S., D’Esposito, V., Oriente, F., Formisano, P., and Di Carlo, A. (2016). Substrate-zymography: a still worthwhile method for gelatinases analysis in biological samples. Clin. Chem. Lab. Med. 54, 1281-1290.

Rybak-Chmielewska, H., and Szczęsna, H. (2006). HPLC study of chemical composition of honeybee (Apis mellifera L.) venom. J. Apic. Sci. 48, 103-109.

Sciani, J. M., Marques-Porto, R., Lourenço Junior, A., Orsi Rde, O., Ferreira Junior, R. S., Barraviera, B., et al. (2010). Identification of a novel melittin isoform from Africanized Apis mellifera venom. Peptides 31, 1473-1479. doi: 10.1016/ j.peptides.2010.05.001

Silva, J., Monge-Fuentes, V., Gomes, F., Lopes, K., dos Anjos, L., Campos, G., et al. (2015). Pharmacological alternatives for the treatment of neurodegenerative disorders: wasp and bee venoms and their components as new neuroactive tools. Toxins 7, 3179-3209. doi: 10.3390/toxins7083179

Upadhyay, R. K. (2014). Drug delivery systems, CNS protection, and the blood brain barrier. Biomed. Res. Int. 2014:869269. doi: 10.1155/2014/869269

Wehbe, R., Frangieh, J., Rima, M., El Obeid, D., Sabatier, J. M., and Fajloun, Z. (2019). Bee Venom: overview of main compounds and bioactivities for therapeutic interests. Molecules 24:2997. doi: 10.3390/molecules24162997

Wolff, J., Trilling, T., Mölenkamp, G., Egeler, R. M., and Jürgens, H. (1999). Chemosensitivity of glioma cells in vitro: a meta analysis. J. Cancer Res. Clin. Oncol. 125, 481-486. doi: 10.1007/s004320050305

Yelken, B. Ö, Balcı, T., Süslüer, S. Y., Kayabaşı, Ç, Avcı, Ç. B., Kırmızıbayrak, P. B., et al. (2017). The effect of tomatine on metastasis related matrix metalloproteinase (MMP) activities in breast cancer cell model. Gene 627, 408-411. doi: 10.1016/j.gene.2017.06.054

Zhang, H., Ma, Y., Wang, H., Xu, L., and Yu, Y. (2019). MMP-2 expression. Oncol Lett. 17, 1826-1832. doi: 10.3892/ol.2018.9806

Zhang, S., Liu, Y., Ye, Y., Wang, X.-R., Lin, L.-T., Xiao, L.-Y., et al. (2018). Bee venom therapy: potential mechanisms and therapeutic applications. Toxicon 148, 64-73. doi: 10.1016/j.toxicon.2018.04.012

Zheng, J., Lee, H. L., Ham, Y. W., Song, H. S., Song, M. J., and Hong, J. T. (2015). Anti-cancer effect of bee venom on colon cancer cell growth by activation of death receptors and inhibition of nuclear factor kappa B. Oncotarget 6 , 44437-44451. doi: 10.18632/oncotarget.6295

Zhou, J., Qi, Y., Diao, Q., Wu, L., Du, X., Li, Y., et al. (2013). Cytotoxicity of melittin and apamin in human hepatic L02 and HepG2 cells in vitro. J. Toxicol. Toxin. Rev. 32, 60-67. doi: 10.3109/15569543.2013.852108

Zhou, J., Zhao, J., Zhang, S., Shen, J., Qi, Y., Xue, X., et al. (2010). Quantification of melittin and apamin in bee venom lyophilized powder from Apis mellifera by liquid chromatography-diode array detector-tandem mass spectrometry. Anal. Biochem. 404, 171-178. doi: 10.1016/j.ab.2010.05.014

Conflict of Interest: The authors declare that the research was conducted in the absence of any commercial or financial relationships that could be construed as a potential conflict of interest.

Publisher's Note: All claims expressed in this article are solely those of the authors and do not necessarily represent those of their affiliated organizations, or those of the publisher, the editors and the reviewers. Any product that may be evaluated in this article, or claim that may be made by its manufacturer, is not guaranteed or endorsed by the publisher.

Copyright (c) 2022 Małek, Kocot, Mitrowska, Posyniak and Kurzepa. This is an open-access article distributed under the terms of the Creative Commons Attribution License (CC BY). The use, distribution or reproduction in other forums is permitted, provided the original author(s) and the copyright owner(s) are credited and that the original publication in this journal is cited, in accordance with accepted academic practice. No use, distribution or reproduction is permitted which does not comply with these terms. 